\title{
EDITORIAL
}

\section{DESDE LA DIVERSIDAD HACIA LA DESIGUALDAD: ¿DESTINO INEXORABLE DE LA GLOBALIZACIÓN?. A MODO DE INTRODUCCIÓN.}

"La esperanza es el sueño del hombre despierto"

(Aristóteles)

En la actualidad no existe objeción en afirmar que la globalización ha potenciado paradigmáticamente el desarrollo de las actividades comerciales transnacionales, el flujo y la movilidad de los recursos humanos, mercantiles y tecnológicos, la transformación demográfica, ecológica y laboral, y la interdependencia de los procesos económicos, productivos, culturales y de comunicación. Del mismo modo es también la globalización quien ha intensificado las disparidades socioeconómicas, las injusticias y la vulnerabilidad asentadas en las condiciones estructurales de vida y los procesos de participación social.

Concientes del impacto descollante que poseen los actuales procesos de exclusión, desafiliación y acumulación social, económica, política y cultural, diferentes organismos internacionales como Naciones Unidas, UNESCO, OIT, CEPAL, UNICEF, PNUD, Banco Mundial, prestigiosos Centros de Investigación y los gobiernos de los Estados mas importantes del mundo coinciden en subrayar la necesidad de superar la pobreza y la exclusión social como condición inexorable para tornar sustentable el actual proyecto de desarrollo global.

En esta trayectoria y a modo de ejemplo en América Latina y Europa, se distinguen en los últimos 10 años algunos esfuerzos invertidos en pos de superar las restricciones estructurales que suponen la exclusión socioeconómica y la marginación cultural. Sin embargo las estrategias implementadas, debido a su carácter provisorio y parcial no abordaron la causa neurálgica de estos problemas que se halla enraizada en la dinámica misma en cómo se produce y reproduce el sistema capitalista mundial.

En este sentido se evidencia también que la exclusión social, el desempleo y la pobreza afectan fundamentalmente a las minorías étnico-culturales, a las mujeres, a los grupos menos educados, a las poblaciones rurales, a los sectores desaventajados económicamente y a las generaciones más jóvenes, quienes además están más propensos a la informalidad laboral, la indefensión político - jurídica y a la privación del acceso a los bienes materiales y simbólicos imprescindibles para poder participar plenamente en la vida social.

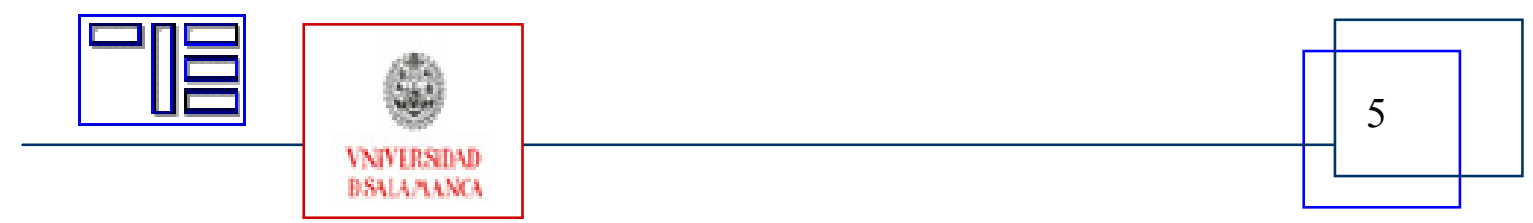


Revista Electrónica Teoría de la Educación.

Educación y Cultura en la Sociedad de la Información.

http://www.usal.es/teoriaeducacion

Vol. 9. No 2. Mayo 2008

La disgregación de los tejidos de integración cultural y la ruptura de las dinámicas tradicionales desde las que se erigían los procesos de socialización y de transición en el ámbito familiar, escolar, institucional y laboral, interpelan la legitimidad del actual modelo de organización político y social poniendo al descubierto la urgencia de replantear política y socialmente el modo en cómo se modulan dichos procesos.

En esta perspectiva también se constata una cierta ausencia de nexos comunicantes entre las diversas culturas (originarias y emergentes) y la cultura oficial (instituida a través del sistema educativo, de las normas jurídicas y de los cánones que ordenan la vida institucional), entre los sectores incluidos, los vulnerables y los excluidos, y así como también entre los países adelantados a nivel económico e industrial y aquellos que aún aguardan por el tan ansiado acoplamiento en el proceso de crecimiento y desarrollo (Aparicio, 2006). Todas estas disociaciones recalan directamente en un ahondamiento de las diferencias planteadas entre "los unos y los otros", que viene a significar el desmembramiento de un nosotros cohesionante e incluyente (Bauman, 2005).

La experiencia en el ámbito de la integración social y cultural global demuestra que la falta de diálogo intercultural, la débil integración social y económica entre los pueblos, y el laxo reconocimiento de la "otredad" en su amplia dimensión, coadyuvan a incrementar la dualización social, los reduccionismos culturales y la asunción espuria de "lo diverso y lo diferente" (Bauman, 2004b).

En la actualidad esta suerte de reificación de las diferencias culturales y socioeconómicas que distingue a "unos de otros" ha propendido a aceptar como un "dado natural y estático" las desigualdades, hecho que tiene por lo menos dos consecuencias, por un lado tiende a ocultar las verdaderas causas que originan las contradicciones sociales como por ejemplo el origen socioeconómico, el nivel educativo de las familias, el tipo de empleo detentado, la procedencia étnica-cultural y racial, que en la mayoría de las sociedades occidentales permiten rastrear la raíz de las distinciones (Bourdieu, 1999b). Mientras que por otro lado, obstaculiza la generación de estructuras cognitivas complejas que favorezcan el conocimiento y el respeto de la diversidad cultural desde un posicionamiento crítico, capaz de valorar -porque experimenta y entiende- el sentido de la pluralidad.

La dinámica cambiante, endeble y polisémica que revisten los actuales procesos de inclusión y de exclusión social más que una excepción se inscriben como la regla general que modula el desplazamiento de la mayoría de los sujetos dentro del espacio social, el sistema educativo, del mercado de trabajo y de la vida política e institucional a nivel global. En esta trayectoria "lo provisorio y lo versátil" se infringen como tendencias inherentes al desarrollo individual y colectivo de las personas (Beck, 1990).

El primado de la inestabilidad, la incertidumbre, lo volátil y lo móvil pasan progresivamente a constituirse en componentes axiomáticos de la vida y de las interacciones sociales. En esta perspectiva Sennet (2000) postula que "la cultura

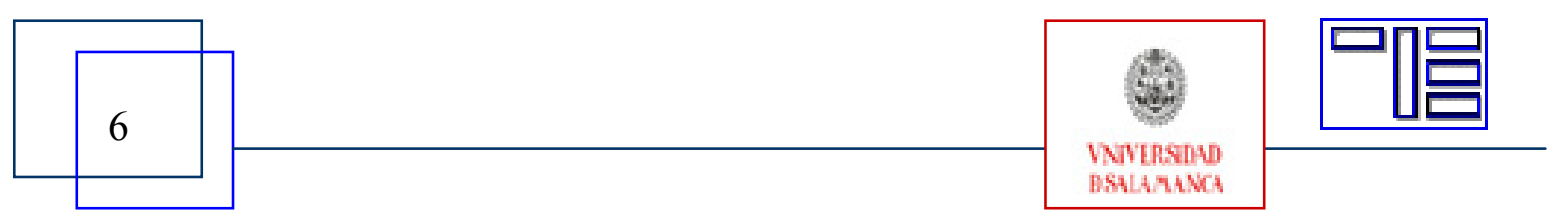


moderna del riesgo se caracteriza porque no moverse es sinónimo de fracaso, y la estabilidad parece casi una muerte en vida. Por lo tanto, el destino importa menos que el acto de partir."1

En los últimos años y pese a los augurios más auspiciosos de quienes proclamaban el advenimiento de una integración mundial a partir de la consagración internacional del sistema capitalista de producción, hoy y en pleno auge de la globalización, ha quedado demostrado que el acceso diferenciado de las sociedades al bienestar y a los servicios sociales elementales y la presencia de procedimientos de segregación socioeconómica, laboral y cultural, impactan significativamente en la configuración de espacios sociales segmentados, heterogéneos y desiguales.

La globalización imbrica y penetra todos los ámbitos de la vida individual y colectiva, en este contexto, el engendramiento de prácticas y dinámicas de distinción, vulnerabilización y exclusión social parecen erigirse como imperativos categóricos desde donde se definen la totalidad de los espacios y las dinámicas de organización social. En esta perspectiva, las desigualdades estructurales prevalecientes en el campo económico, laboral, social, político, institucional y cultural han tendido a perpetuar las diferencias subyacentes que operan tanto en el interior de las sociedades (entre los diferentes grupos sociales), y así como también entre los países industrializados y los países en vías de desarrollo (entre el norte y el sur).

Con lo expuesto, queremos insistir en la tesis que sostiene que, empero al crecimiento económico macro estructural, la expansión productiva y la flagrante internacionalización de las actividades financieras $y$ el soporte tecnológico $y$ comunicacional evidenciables en nuestros días, no existen alegatos contundentes que demuestren que se haya avanzado paralelamente en la superación de los antagonismos socioeconómicos (Machinea y Hopenhayn, 2005; Chomsky, 2000), en el contrarrestamiento de la disolución de los valores éticos y el agotamiento de las vías institucionales de consenso político (Bauman, 2004), en el desmembramiento del estado y en el basamento jurídico de la cohesión social (O’Donnell, 2001), en la homogenización cultural que oculta la pluralidad y amedrenta las diferencias idiosincrásicas e identitarias locales (Hopenhayn, Bello y Miranda, 2006), en la depredación irresponsable del medio ambiente y la biodiversidad, y finalmente, en la exacerbación del liderazgo del mercado concebido como único organizador de la vida social y que bloquea la gestación de un modelo politico de desarrollo que sea más incluyente, democrático y sustentable (Boeckh, 2002; Jäger, 2002; Krumwiede, 2002).

En los hechos, queda evidenciado que a pesar de los esfuerzos acometidos por algunos gobiernos de la región y entidades vinculadas a la cooperación internacional para el desarrollo en torno al abordaje de los efectos nocivos de la expansión económica, productiva y financiera global, aún no se ha podido resolver la verdadera naturaleza de las causas históricas que obstruyen la inclusión socioeconómica (dentro y entre las sociedades) y la participación de los ciudadanos en todas las instancias de la vida

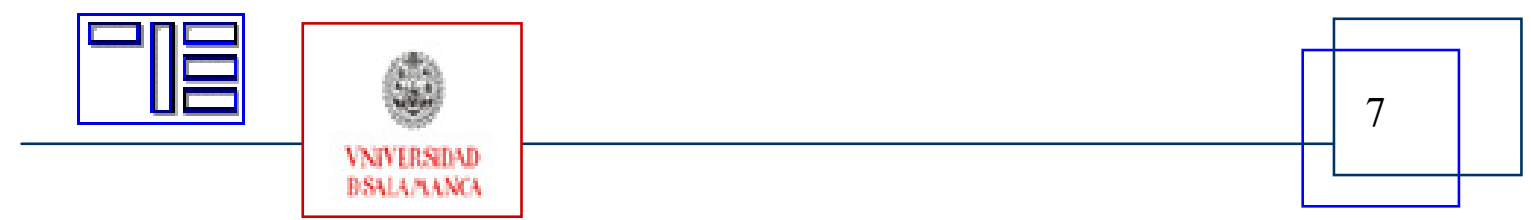


Revista Electrónica Teoría de la Educación.

Educación y Cultura en la Sociedad de la Información.

http://www.usal.es/teoriaeducacion

Vol. 9. No 2. Mayo 2008

política, institucional y cultural.

Al respecto los indicadores socioeconómicos más fehacientes revelan que el problema de la desigualdad, la precariedad y el riesgo social están enraizados en condiciones estructurales como, por ejemplo, la sustentabilidad de los procesos económicos y productivos, el nivel de equidad social, el acceso a los servicios sociales, la cohesión y la estabilidad política e institucional, la funcionalidad y transparencia de los sistemas de gobierno, la eficiencia administrativa de los servicios públicos, el acceso al trabajo decente y productivo, la convivencia sana con el medio ambiente y el ecosistema, la seguridad y la protección social; el modo de producción, de distribución y de acumulación de la riqueza, de las posibilidades individuales y colectivas de autodeterminación, etcétera.

Una de las contradicciones más elocuentes de la globalización se manifiesta en la disociación planteada entre a) el grado de desarrollo y de expansión conquistado por la economía, las inversiones del capital y las transacciones financieras (globalismo económico) y b) las posibilidades objetivas que detentan los ciudadanos para poder acceder a los bienes materiales y simbólicos que producen y ponen a disposición el actual sistema económico y productivo global (Beck, 1999).

La concentración del bienestar que se cristaliza a través de la acumulación de los empleos calificados, las posibilidades de desarrollo profesional y la protección social y laboral ha incrementado las brechas diferenciadoras entre los grupos sociales y las naciones, y así como también ha acentuado significativamente los desplazamientos humanos en la vasta dimensión del globo. ${ }^{2}$ Por esta razón, la globalización que hoy experimentamos más que un "espacio de lugares" debería ser entendida como un "espacio de flujos", donde el tránsito y la volatilidad de los intercambios y el ímpetu de la circulación de bienes, de servicios y de constructos culturales exponen su mayor característica (Castells, 1996).

En este escenario los movimientos migratorios y los grandes desplazamientos humanos traen aparejados la disgregación de los nexos familiares, la transformación de las referencias culturales y la identidad y la confrontación de cosmovisiones entre los grupos inmigrantes y los grupos receptores.

La búsqueda de mejores posibilidades de vida revela el intento de los hombres por incorporarse a un sistema social y económico más próspero y sostenible, pero es de aquí que esta búsqueda en reiteradas ocasiones no se concreta y más bien deriva en una mayor propensión a la precariedad, a la explotación y a la vulnerabilidad social.

En un reciente informe elaborado por Naciones Unidas (2005) se estima que existen más de 200 millones de inmigrantes a nivel internacional, considerando esta tendencia en crecimiento continuo. Por su parte la Organización para la Cooperación y el Desarrollo Económicos (OECD) vaticina que en el 2005 el porcentaje correspondiente

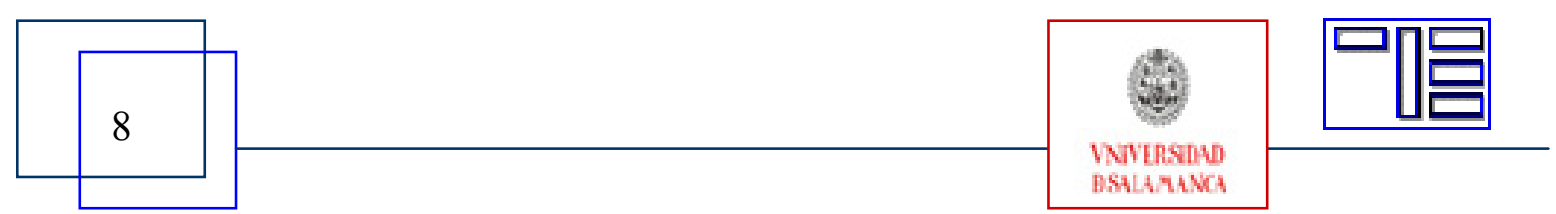


al flujo inmigratorio permanente en los países desarrollados se incrementó en una tasa anual del 10\%. El fenómeno migratorio reviste aspectos de índole estructural, lo que a veces torna incomprensible y pavorosa la falta de un debate "más allá de las fronteras locales" sobre la inclusión social y económica a nivel global que pondere la equiparación de los estándares de empleo y productividad, las condiciones de vida y seguridad social, el aval jurídico de los emprendimientos productivos, las posibilidades objetivas de vivir y transformar el legado cultural, etcétera.

Esta nueva forma de asumir la complejidad de la realidad debería sobrepasar los pragmatismos y las percepciones simplistas y antagónicas que suelen exacerbar los temores, los prejuicios y la descalificación preventiva de lo desconocido y lo foráneo (Castel, 2004).

La imposibilidad de participar libre y plenamente en el sistema económico global refleja progresivamente la inoperancia de los procesos de integración y cohesión social frente a los desafíos que infringen la desigualdad socioeconómica, la pluralidad cultural, la irresponsabilidad ecológica y la endeble organización democrática de la vida política e institucional (Ferrer, 2000).

La evasión de cualquier posibilidad de diálogo intercultural abierto y plural, tergiversa el sentido mismo de la interculturalidad que penetra vertiginosamente la vida de las sociedades, y que en la actualidad está exigiendo la descentración del pensamiento y un tratamiento más exhaustivo de la hibridación cultural a la que asistimos hoy en día (García Canclini, 1990; 1995).

Estas tendencias paralelas y escindidas que coexisten en el actual modelo de desarrollo global, lejos de representar anomias coyunturales desvelan la debilidad de los postulados integracionistas -sustentados por la elite económica y empresarial- que persisten en sostener que a partir de la consagración del sistema capitalista, las desigualdades estructurales tenderían a mitigarse casi por antonomasia, gracias al impacto positivo e incluyente de la prosperidad económica (Hobsbawn, 2007; Bauman, 2000).

En el ámbito político y económico se puede distinguir también la irrupción de planteamientos tecnocráticos y racionalistas que propugnan por el liderazgo del mercado como única vía del desarrollo, el rol estratégico del capital privado y el apartamiento del estado como garante social primero, premisas que encuentran en los cánones conceptuales del neoliberalismo -en su versión más ortodoxa- sus fundamentos axiales.

En esta perspectiva, se constata como, por ejemplo, en América Latina y progresivamente en diferentes países de Europa la sustitución del intervencionismo estatal (Welfare State) por las libertades del mercado, la necesidad de establecer la disciplina fiscal y la participación progresiva de la sociedad civil en la gestión y en el

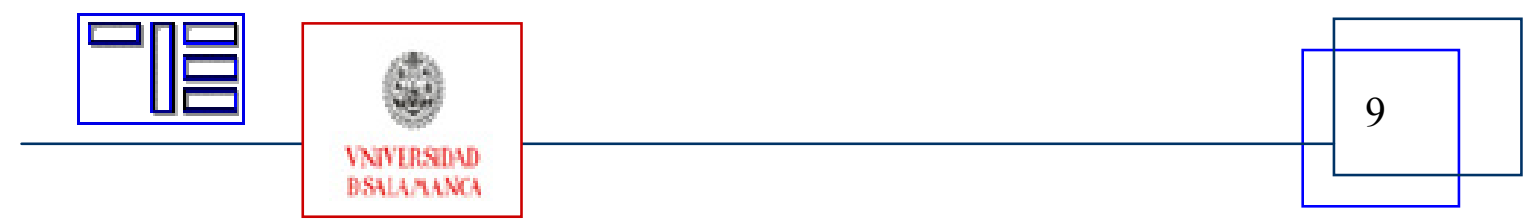


Revista Electrónica Teoría de la Educación.

Educación y Cultura en la Sociedad de la Información.

http://www.usal.es/teoriaeducacion

Vol. 9. No 2. Mayo 2008

financiamiento de los servicios públicos -vía privatización y descentralización económica- se condice con el desdibujamiento de las responsabilidades políticas y sociales del estado en materia de compensación de las desigualdades y de la disgregación de las redes institucionales de cohesión y de representación social.

La impronta de esta nueva ideología propende a generar programas y acciones orientados a abordar desde una perspectiva focal, asistencialista y coyuntural los problemas ligados a la exclusión sociocultural, al desempleo, a la pobreza, a la desintegración étnica cultural y la baja participación civil y política, descuidando muchas veces la dimensión estructural, local y singular de los grupos humanos afectados (Beck y Bondß, 2001; Gorz, 1999; Aparicio, 2006b).

En este sentido se podría concluir que la complejización y heterogeneización del tejido social conjugadas a la debilidad de las instituciones del estado, tornan aún más inverosímil poder imaginar y esperar una genuina transformación de estos conflictos acuciantes (Touraine, 2006).

El primado de la economía como único criterio ordenador en el caso particular del ámbito educativo propende a desdeñar la heterogeneidad de los escenarios y los procesos educativos y sociales, evadiendo una aproximación real y compleja a los aspectos más conflictivos.

La desigualdad regente en la arena educativa expone la existencia de sistemas de formación paralelos y diferenciados, que están fuertemente enraizados en el nivel socioeconómico de los grupos humanos y la situación geográfica, cultural, étnica y de género que ha tendido sistemáticamente a profundizar la desigualdad social y la segmentación de las oportunidades de participación social, laboral y económica (UNESCO, 2007). En esta perspectiva y coincidiendo con Bourdieu (1999) se podría añadir que "cuando los poderes están desigualmente repartidos, el mundo económico y social no se presenta como un universo de posibles igualmente accesibles a todo sujeto posible - puestos que ocupar, estudios que hacer, mercados que conquistar, bienes que consumir, posesiones que intercambiar, etcétera-, sino más bien como un universo señalizado, lleno de conminaciones y prohibiciones, de señales de apropiación y exclusión, de direcciones prohibidas o barreras infranqueables y, en una palabra, profundamente diferenciado."3

El bajo perfil de las respuestas de los sistemas educativos a las demandas del ámbito laboral, económico y cultural no ha podido aún corregirse pese a la intromisión de programas y reformas implementadas recurrentemente en América Latina y en algunos países de Europa en los últimos 20 años.

La correlación planteada entre las desigualdades sociales y económicas y las posibilidades efectivas de participación de los actores en el campo de formación da cuenta de la importante segmentación instalada en el seno del sistema educativo y en su

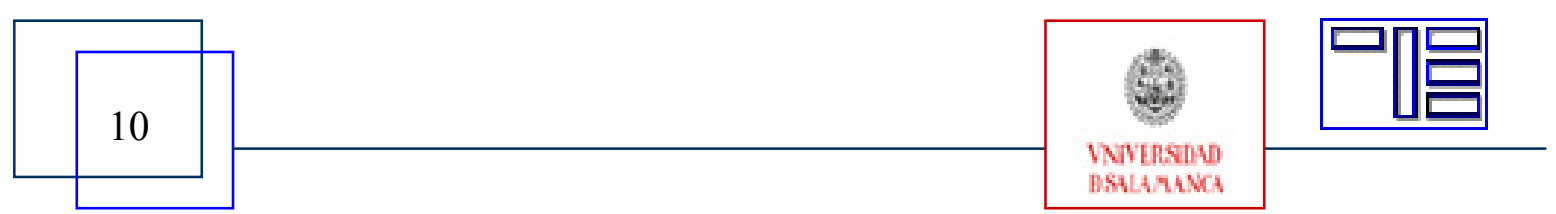


articulación con las condiciones de vida de las personas y con las trayectorias biográficas de los sujetos dentro del mercado laboral y la vida adulta. A propósito, recientes estudios corroboran que las ofertas laborales y educativas de calidad son captadas casi "exclusivamente" por los sectores más educados y mejor posicionados en la jerarquía social, es decir quedan bajo el dominio de los sectores medios y altos generalmente- para los que los nuevos desafíos del mercado de trabajo y la vida social no suponen una barrera insorteable, a diferencia de los sectores sociales vulnerables que parcial o absolutamente- se hallan desprovistos de las herramientas educativas y culturales mínimas para pelear la inclusión social (CEPAL et al., 2007; Naciones Unidas, 2007; OIT, 2005; Banco Mundial, 2006; UNESCO y BMZ, 2005).

La progresiva monopolización de las ofertas de formación educativa y los contenidos cognitivos, psicosociales y culturales (capital social) demuestra el carácter desigual y fragmentario que revisten los actuales procesos de socialización educativa en América Latina y en algunos países de Europa que afectan fundamentalmente a las minorías étnica-culturales y a los grupos sociales más desaventajados (Morrow, Apple, Popkewitz et al., 2005).

En consideración a la complejidad de los procesos de integración y exclusión social, laboral y educativa prevalecientes en el contexto de la globalización se abordará aquí desde una mirada crítica e interdisciplinaria- la relación planteada entre la desigualdad socioeconómica y los contextos de pluralidad cultural enfatizando la dimensión de los actuales y futuros procesos de inclusión social, el aporte de las nuevas tecnologías en la organización de la oferta educativa, la impronta de los desplazamientos demográficos a nivel local e internacional, la inclusión laboral y la pugna por el reconocimiento cultural de las minorías.

En una primera instancia Silvia Mongili analiza algunas tensiones planteadas entre las tendencias de cambios globales y locales en la vida social, concentrándose específicamente las implicaciones de los esquemas racionales y culturales hegemónicos y mundiales que alteran el modo en como las personas representan el mundo, perciben al otro (alteridad) y proyectan sus propias vidas. Al respecto, la autora reflexiona también sobre la situación de las minorías étnico-culturales y sus posibilidades concretas de conservar y ampliar el desarrollo de su patrimonio cultural. Para culminar se aproxima la experiencia realizada por dos proyectos educativos en Guatemala, uno destinado a la empoderización (empowerment) de las redes sociales locales y el otro, orientado a la organización de la Universidad Maya. Como se observara ambas propuestas apuestan el sostenimiento de la diversidad cultural existente, el reconocimiento de lo local y el abordaje crítico de los impactos multifacéticos de la globalización cultural.

El reconocimiento de las culturas originarias sigue presentando déficits estructurales evidenciables, por ejemplo, en la organización de los mecanismos institucionales, jurídicos y políticos destinados a la formación y capacitación de las personas

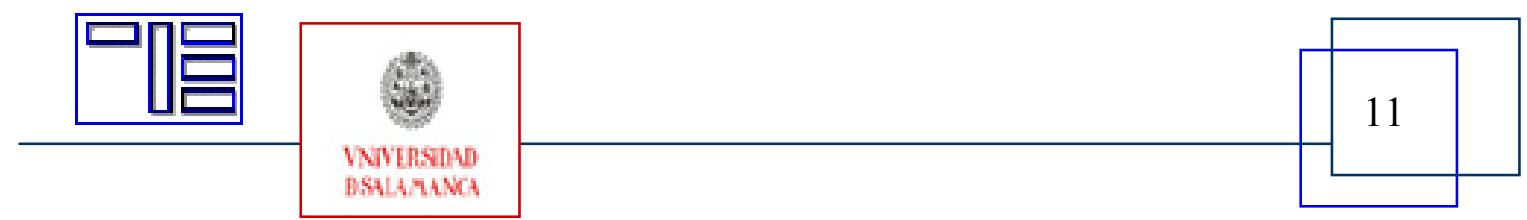


pertenecientes a grupos culturales diferentes. En esta perspectiva Christina Goschenhofer, Santos de la Cruz Carrillo y Carlos Chávez Reyes aproximan el ejemplo de la comunidad Wixaritar en México que revela las formas en como interactúa la cultura oficial y sus mecanismos de asimilación frente a los procesos de reconocimiento de las culturas locales y originarias, que no sólo se diferencian de la primera, sino que además son negadas por esta. Ante la ausencia de un diálogo intercultural complejo y dialéctico, la posibilidad de vivir la diversidad parece caer en desmedro, poniendo en clara evidencia el poder homogeneizante coactivo que encarna el modelo cultural instituido.

En una perspectiva de análisis análogo Ursula Stiegler indaga en el contexto político educativo de América Latina, la tensión sostenida entre la asimilación aculturalizante y el reconocimiento del otro, como dos formas antagónicas de visibilizar y promover las demandas y exigencias de los grupos culturalmente diversos. A partir de la ponderación de la situación de la comunidad Mapuche en Chile, se ejemplifica exponencialmente cómo empero a las "bien intencionadas" políticas de integración y cohesión que a nivel nacional buscan la incorporación de las minoridades étnicas a la civilidad y a la identidad cultural unificada, se sigue desmedrando las posibilidades reales que los grupos originarios poseen para autodeterminarse y preservar legítimamente sus propios acervos culturales.

El acceso a los bienes y a las oportunidades concedidas por las nuevas tecnologías de la comunicación parecen estar fuertemente condicionadas por la situación sociohistórica y cultural desde donde las personas organizan -a nivel individual y colectivo- sus mecanismos de participación dentro de un mundo cada vez más globalizado. En este sentido hablamos de una articulación dialéctica erigida entre las oportunidades de acceso, manipulación y transformación de los conocimientos y las informaciones que circulan en el espacio virtual y la situación social e histórica de vida de las personas y las comunidades.

Compenetrados con esta situación Pablo Christian Aparicio y Maria del Carmen Silva Menoni aportan una reflexión a cerca de la educación y los desafíos de la integración de las nuevas generaciones en un contexto global, tomando como referencia primordial el aporte de las nuevas tecnologías en el proceso de participación y transformación educativa en América Latina. Este articulo brinda una clara apreciación histórica y política de la actual propuesta educativa, para poder comprender a donde residen sus límites y potencialidades al momento de pensar en una genuina reforma que considere el aporte de las Tecnologías de la Información y Comunicación (TIC) sin descuidar la democratización de las condiciones de participación educativa, el reconocimiento de la diversidad cultural y el apoyo socio pedagógica a todos los sectores sociales, especialmente a los grupos más vulnerables.

Ahora bien, numerosos estudios coinciden en sostener que la participación o no de las ventajas concedidas por las Tecnologías de la Información y Comunicación (TIC)

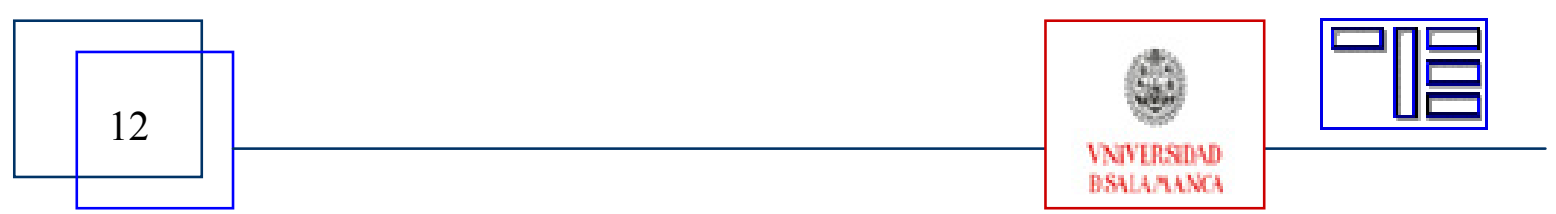


constituye un arma de doble filo, a saber, por un lado, la participación en las TIC resulta un medio significativo de apoyo a los procesos de inclusión social que habilita la ampliación de los horizontes cognoscitivos y culturales, mientras por otro lado, la noparticipación en las mismas opera como un mecanismo selectivo que ahonda los procesos de segregación social y reproduce el rezago cultural y educativo subyacente. Compentrado con esta problemática y advirtiendo sobre los peligros que engendra para las minorías étnicas culturales la imposibilidad de participar en las TIC y en la sociedad de información, Evaristo Orvide elabora un interesante análisis referido a las posibilidades de conservar el patrimonio cultural utilizando las facilidades de Internet en esta empresa, a los fines de garantizar la elaboración de vías efectivas de inclusión sociocultural.

Como es sabido, el acceso a la educación define gran parte las trayectorias biográficas y sociales de las personas, he ahí su impronta y la dimensión potencial de su aporte. Por este motivo, evaluar la forma en como los grupos humanos participan de la educación, se apropian del capital cultural y aprenden a desempeñarse adecuadamente en la vida social, representan aspectos neurálgicos a ponderar en el debate sobre cómo definir y construir condiciones equitativas de participación educativa y sociocultural de vida. Marcelo Parreira do Amaral, tomando como referencia la participación en el sistema educativo superior de los grupos con ascendencia africana en Brasil, analiza los mecanismos y las instancias de acceso a la educación en un contexto socio histórico atravesado por la desigualdad socioeconómica y los límites estructurales basándose en el aporte teórico de la "world polity".

Dorando Michelini cuestiona el aporte de la universidad frente a los actuales desafíos sociales, entendiendo a esta institución como un espacio estratégico de formación educativa y social, en donde están en juego las oportunidades reales y potenciales de participación de las generaciones jóvenes en la vida pública. Desde una mirada filosófica y ética se refiere a la interculturalidad subyacente en las sociedades actuales y a las posibilidades que detenta la universidad para construir espacios de integración y participación democrática, fortalecer la sociedad civil y luchar contra las restricciones sociales imperantes, a partir de la construcción de un discurso público que identifique y objetive la voluntad de los diferentes sectores sociales.

Circunscrito en un escenario más complejo y abarcador Mauricio Salazar estudia la conformación de nuevos grupos y procesos de organización social a partir del fenómeno de la integración a escala mundial. En este trabajo se exploran las causas, las consecuencias y las peculiaridades de este fenómeno paradigmático de nuestro tiempo, considerando especialmente las transformaciones en las formas de percibir el mundo que va aparejada a un cambio cultural profundo e irreversible que hoy por hoy atraviesa la cotidianeidad tanto de las sociedades que expulsan como así también de las sociedades que reciben a los inmigrantes en la vasta extensión del globo.

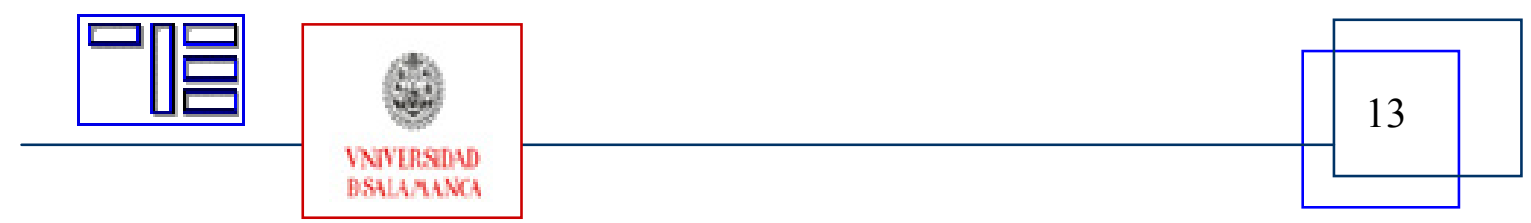


Revista Electrónica Teoría de la Educación.

Educación y Cultura en la Sociedad de la Información.

http://www.usal.es/teoriaeducacion

Vol. 9. No 2. Mayo 2008

En alusión a la impronta que traen consigo los procesos migratorios y la incertidumbre que genera para los grupos autóctonos como foráneos la modificación de las referencias culturales e identitarias, Alfredo Astorga esboza una lectura sobre los aspectos constitutivos de los procesos de segregación y exclusión social constreñidos en la condición de inmigrante en el contexto específico de América Latina. Este aporte repara especialmente en el significado de la diversidad cultural y plantea la necesidad de avanzar en la reflexión de las condiciones económicas y materiales que la sustentan.

Los procesos migratorios en la actualidad son una constante dentro de las dinámicas de transformación cultural, económica, ecológica y laboral en boga. Los hombres movidos por la necesidad de mejorar sus perspectivas de vida y el nivel de bienestar afrontan la empresa migratoria con múltiples e imprevisibles riesgos y consecuencias. Al respecto Fernando Ruiz Peyré indaga sobre las causas de los desplazamientos producidos desde las zonas rurales hacia las zonas urbanas, tomando como ejemplo una región ubicada en el centro oeste de Argentina. En este estudio se demuestra cómo la escisión planteada entre los proyectos de superación de los jóvenes y las inviabilidades estructurales del medio social propende a reforzar la pobreza y las condiciones de vulnerabilidad, que se pretendían superar a través del éxodo que la apuesta migratoria significa.

La búsqueda de nuevos criterios teóricos y prácticos que posibiliten la organización efectiva de ofertas educativas formales y no formales es un proceso que está fuertemente constreñido con el reconocimiento y en la ponderación de las necesidades de los diversos grupos sociales y culturales en un colectivo determinado. Este proceso no siempre resulta una empresa sencilla y armónica, puesto que se enmarca en uno de los espacios más álgidos y estratégicos de como se distribuyen las posibilidades de participación social y por lo mismo está impregnado de contradicciones, disensos y luchas de poder.

Sin embargo, la educación representa para muchos grupos sociales una de las escasas cuando no la única posibilidad para poder aspirar a la inclusión social y al desarrollo de sus competencias cognitivas, afectivas y sociales que le facilitarán luego la incorporación al mercado de trabajo y a la vida adulta. En esta perspectiva Karin Elinor Sauer y Sílvio Correa de do Souza, partiendo de un estudio realizado en el sur de Brasil con jóvenes excluidos, nos ilustran un ejemplo concreto de como la contribución de la educación obra en la transformación de la vida biográfica y social de las personas, promoviendo estrategias de superación y ayudando al mejoramiento de la calidad de vida.

Por su parte Christine Riegel reflexiona sobre los procesos de integración y reconocimiento dentro de un contexto social diversificado, subrayando la necesidad de construir una genuina igualdad de oportunidades más allá de las diferencias enraizadas en el género, la procedencia étnica cultural y el emplazamiento social y económico de los actores en la estructura social. En este artículo se recala también en la necesidad de apoyar sistemática y congruentemente el desarrollo de estrategias y alternativas locales

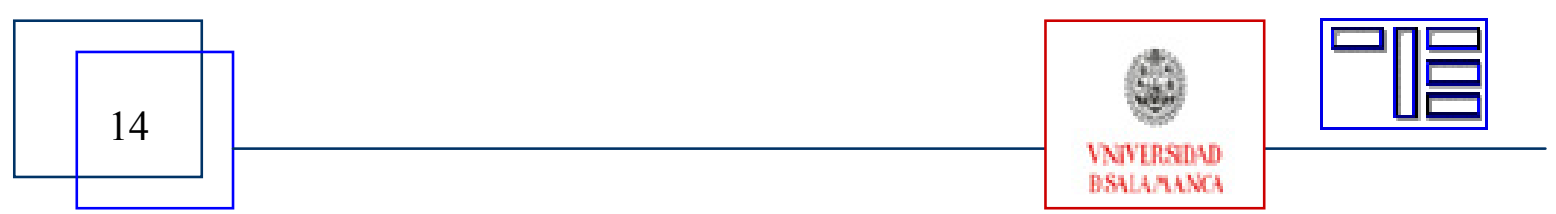


para poner fin a la exclusión social a través de un mejor acceso a los beneficios sociales, laborales y educativos, así como también de una implicación efectiva de los sujetos con las estrategias y los programas políticos extendidos desde el estado y sus diferentes dispositivos institucionales.

Desde una mirada socio pedagógica Carola Flad y Eberhard Bolay indagan sobre las estrategias de intervención destinadas a orientar y promover a los grupos inmigrantes en sus procesos de integración dentro del ámbito escolar en Alemania. Las propuestas extendidas desde el Estado buscan reparar los déficits y restricciones que se amalgaman con los contextos sociales atravesados por la vulnerabilidad y las limitaciones socioeconómicas. Este estudio subraya la importancia que adquieren las acciones de compensación paralelas a las ofertas educativas formales en razón a promover estratégicamente tareas de apoyo, orientación y acompañamiento de los procesos de inclusión social de los grupos más desaventajados.

Valentina Maya Frades analiza la situación socio educativa de las mujeres inmigrantes en la sociedad española sopesando el grado de articulación existente entre los mecanismos de integración cedidos por el sistema educativo y las políticas sociales, y las demandas reales del grupo objetivo. En el artículo se intenta demostrar la vasta dimensión y el impacto social que conlleva la diversidad cultural interpelando las reglas y los valores de la sociedad española y europea. La autora plantea la necesidad de analizar de forma sustancial y compleja la inmigración dentro del escenario educativo para evitar el cultivo de descalificaciones xenófobas, la reproducción de estereotipos basados en el prejuicio y la injusticia social catapultadas desde la discriminación del género.

Como ya se expuso, los procesos migratorios tanto a nivel nacional como internacional conllevan aparejados confrontaciones, contradicciones y retos que parecen interpelar los fundamentos mismos de la cohesión social subyacente. El trabajo y los procesos de participación productiva representan sin duda uno de los temas más concomitantes en el debate de la integración global, sobre todo estando situados en un contexto donde prevalecen las reglas inherentes al mercado mundial de producción. Contiguamente a ello se manifiestan los procesos ligados a la carencia y las restricciones del empleo y así también el resquebrajamiento de los mecanismos sociales tradicionales de formación y preparación para la vida laboral. En este sentido Alessandra Muriano se concentra en el análisis del proceso de participación social gestado dentro y a través del mercado de trabajo en la sociedad italiana, concentrándose fundamentalmente en la situación del colectivo inmigrante.

La amplia diversidad de aportes de investigadores y posicionamientos científicos sistematizados en el presente número de la Revista Teoría de la Educación nos permitirá introducirnos en el debate sobre las actuales dinámicas de inclusión y exclusión que operan en el campo socioeconómico, laboral, geográfico y educativo en determinados países y regiones de América Latina y Europa.

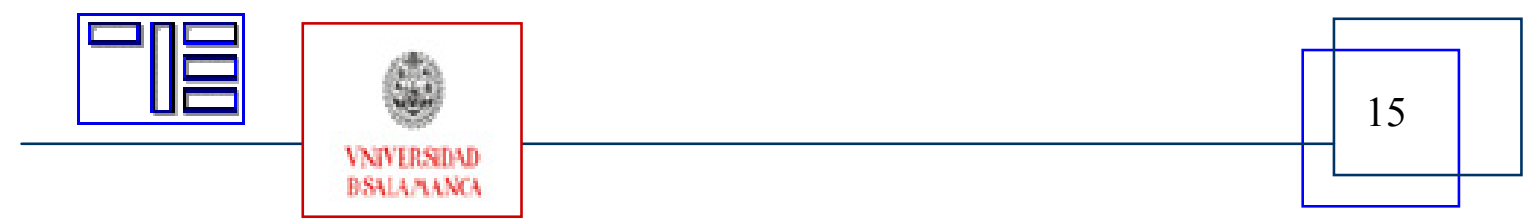


El mayor propósito de la presente contribución académica radica en la búsqueda plural de estrategias y orientaciones críticas que nos aproximen ideas y posibilidades en virtud a repensar la relación planteada entre la desigualdad socioeconómica y la segregación cultural que subyacen en la globalización que hoy vivimos.

La transformación de las condiciones restrictivas y denigrantes de vida, a nuestro juicio, debe inexorablemente iniciarse en la toma de conciencia de esta situación, para evitar que la compleja y problemática realidad histórica social que vivimos nos entrape, someta e inmovilice. En esta idea fuerza, se fundamenta el sentido del presente aporte científico e interdisciplanario que hoy deseamos compartirles, conscientes de que sólo juntos podemos construir otro mundo, donde la integración no sea un privilegio y la convivencia sea más que un decoro retórico o una utopía lejana!

El coordinador:

Pablo Christian Aparicio

\section{REFERENCIAS}

APARICIO, P. CH. (Comp.) (2006). Niños y jóvenes en la encrucijada de la exclusión. ERASMUS Revista para el Diálogo Intercultural,VIII, (1).

APARICIO, P. CH. (2006b). El impacto de las reformas educativas y la constitución del nuevo escenario socio educativo de los jóvenes en América Latina. Una aproximación crítica. Revista Iberoamericana de Educación, 39, (2). Recuperado el 10 de abril de 2008, de http://www.rieoei.org/deloslectores/1353Aparicio.pdf

BANCO MUNDIAL (2006). World Development Report 2007, Development the next Generation. Washinton DC: World Bank.

BAUMAN, Z. (2000). Liquid Modernity. Cambridge: Polity Press.

BAUMAN, Z. (2004). La sociedad sitiada. Buenos Aires: Fondo de Cultura Económica.

BAUMAN, Z. (2004b). Voglia di comunità. Bari- Roma: Laterza.

BAUMAN, Z. (2005). Dentro della globalizzazione. Le conseguenze sulle persone. Bari - Roma: Laterza.

BECK, U. (1990). Risikogesellschaft. Auf dem Weg in eine andere Moderne. Frankfurt am Main: Suhrkamp.

BECK, U. (1998). ¿Qué es la globalización? Falacias del globalismo, respuestas a la globalización. Barcelona: Editorial Paidós.

BECK, U. Y BONDß, W. (2001). Modernisierung moderner Gesellschaften. Frankfurt am Main: Suhrkamp.

BOECKH, A. (2002). Neoliberalismus und soziale Gerechtigkeit in Lateinamerika. En P. BENDEL \& M. KRENNERICH (Eds.): Soziale Ungleichheit. Analysen zu Lateinamerika, (pp. 137-153). Frankfurt: Vervuert.
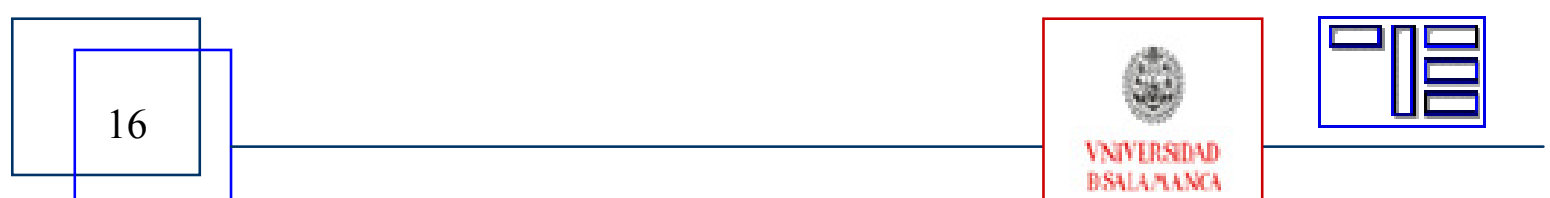
BURCHARDT, H. J. (2003). Tiempos de cambio: Repensar América Latina. El Salvador: Fundación Heinrich Böll.

BOURDIEU, P. (1999). Contrafuegos. Reflexiones para servir a la resistencia contra la invasión neoliberal. Barcelona: Anagrama.

BOURDIEU, P. (1999b). Meditaciones pascalianas. Barcelona: Editorial Anagrama.

CASTEL, R. (2004). La inseguridad social ¿Qué es estar protegido?. Buenos Aires: Manantiales.

CASTELLS, R. (1996). The rise of the Network Society. Oxford: Blackbell Publishers.

CEPAL, AGENCIA ESPAÑOLA DE COOPERACIÓN INTERNACIONAL y SECRETARÍA GENERAL IBEROAMERICANA (2007). La equidad social. Inclusión y sentido de pertenencia en América Latina y el Caribe. Santiago de Chile: CEPAL.

COMISIÓN MUNDIAL SOBRE LAS MIGRACIONES (2005). "Migración en un mundo interconectado". New York: Naciones Unidas.

CHOMSKY, N. (2000). El beneficio es lo que cuenta. Neoliberalismo y orden global. Barcelona: Libros de Crítica.

CHOMSKY, N. y DIETERICH, H. (1999). La aldea global,. México: Txalaparta.

FERRER, A. (2000). Historia de la globalización 2. La revolución industrial y el segundo orden mundial. Buenos Aires: Fondo de Cultura Económica.

GARCÍA CACLINI, N. (1990). Culturas hibridas. Estrategias para entrar y salir de la modernidad. México: Edutorial Grijalbo.

GARCÍA CACLINI, N. (1995). Consumidores y ciudadanos. Conflictos multiculturales de la globalización. México: Editorial Grijalbo.

GORZ, A. (1999). Arbeit zwischen Misere und Utopie. Frankfurt a.M.: Suhrkamp.

HOBSBAWN, E. (2007). Guerra y paz en el siglo XXI. Barcelona: Crítica.

HOPENHAYN, M., BELLO, A. Y MIRANDA, F. (2006). Los pueblos indígenas y afrodescendientes frente al nuevo milenio, CEPAL / GTZ, Santiago de Chile

JÄGER, J. (2002). Politökonomische Transformationsprozesse und Sozialpolitik in Lateinamerika. En P. Bendel \& M. Krennerich (Eds.): Soziale Ungleichheit. Analysen zu Lateinamerika, (pp. 154-176). Frankfurt: Vervuert.

KRUMWIEDE, H. W. (2002). "Soziale Ungleichheit und Massenarmut in Lateinamerika". SWP-Studie 18. Berlin: SWP.

MACHINEA, J. L. Y HOPENHAYN, M. (2005). La esquiva equidad en el desarrollolatinoamericano: una visión estructural, una aproximación multifacético. Serie Informes y Estudios Especiales, No 14. Santiago de Chile: CEPAL.

O'DONNELL, G. (2001). La irrenunciabilidad del Estado de derecho, Instituciones y Desarrollo, $\mathrm{N}^{\circ}$ 8. Barcelona: Institut Internacional de Governabilitat de Catalunya. Recuperado el 21 de marzo de 2008 e http://www.iigov.org/id/article.drt?edi=187536\&art=187545

MORROW, R.; APPLE, M.; POPKEWITZ, T., et AL. (2005). Globalización y Educación, Manual crítico. Madrid: Editorial Popular.

SENNET, R. (2000). La corrosión del carácter: las consecuencias personales del trabajo en el nuevo capitalismo. Barcelona: Ed. Anagrama.

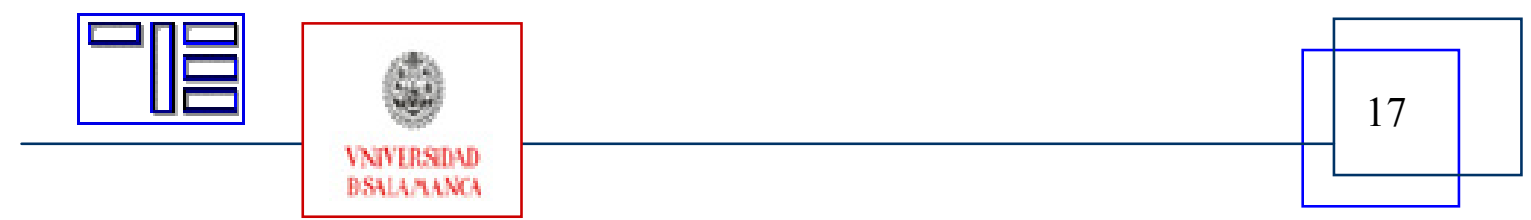


Revista Electrónica Teoría de la Educación.

Educación y Cultura en la Sociedad de la Información.

http://www.usal.es/teoriaeducacion

Vol. 9. No 2. Mayo 2008

TOURAINE, A. (2006). Un nuevo paradigma para comprender el mundo de hoy. Argentina: Editorial Paidós.

OECD (Organización para la Cooperación y el Desarrollo Económicos) (2006). Factbook OCDE. México: OCDE y Mayol Ediciones.

OIT (2005). Objetivos de Desarrollo del Milenio. Informe de 2005. Nueva York: Naciones Unidas.

Naciones Unidas (2005). The inequality predicament. Report on the World Social Situation 2005. Nueva York: Naciones Unidas.

UNESCO (2007). Bildung für alle. Bonn: UNESCO.

UNESCO / BMZ (2005). Weltbericht. Bildung für alle 2006. Kurzfassung. Bonn: BMZ.

\title{
Notas:
}

\begin{abstract}
${ }^{1}$ Op.cit. pág. 45
${ }^{2}$ Al respecto comenta Burchardt (2003) que "la globalización no es un proceso integral que abarque al mundo entero, sino que es más bien la expresión contradictoria de un globalismo neoliberal, caracterizado por procesos simultáneos de integración y fragmentación. Por lo tanto, la integración económica de la globalización, tantas veces evocada, se limita en el fondo a los Estados de la OECD. En este espacio, se efectúa más de la mitad de las transacciones económicas globales y la mayor parte del comercio intraindustrial. Por ejemplo, entre 1980 y 1999, el porcentaje del comercio bilateral entre los países industrializados creció del $45 \%$ al $49 \%$. Aquí es que también se efectúa cerca del $80 \%$ de todas las inversiones directas y que se mueven montos de mil millones de las especulaciones financieras.
\end{abstract}

Esta concentración de los Estados con el perfil de la OECD tampoco es un fenómeno históricamente nuevo, sino que en términos cuantitativos es el mismo fenómeno de internacionalización económica que ya se observaba en el siglo XIX." Op. cit. pág. 72

${ }^{3}$ Op.cit. pág. 298

Para citar este editorial puede utilizar la siguiente referencia:

APARICIO, Pablo (2008). Desde la diversidad hacia la desigualdad: ¿destino inexorable de la globalización? A modo de introducción. En APARICIO, Pablo (Coord.) Desde la diversidad hacia la desigualdad: ¿destino inexorable de la globalización? [monográfico en línea]. Revista Electrónica Teoría de la Educación: Educación y Cultura en la Sociedad de la Información. Vol. 9, $\mathrm{n}^{\circ}$ 2. Universidad de Salamanca. [Fecha de consulta: dd/mm/aaaa].

$<\mathrm{http}: / /$ www.usal.es/ teoriaeducacion/rev_numero_09_02/n9_02_editorial.pdf > ISSN 1138-9737
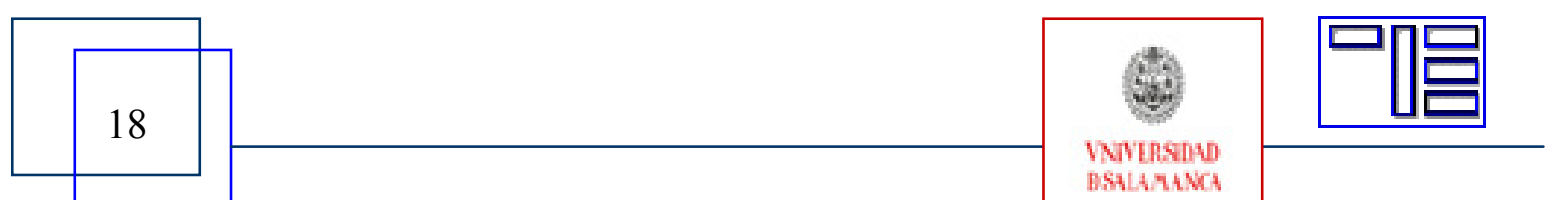